\title{
A case-control study on psychotropic substance use and risk of Axis I psychiatric disorders in HIV-infected gay or bisexual men in Hong Kong
}

Chi Kei Krystal Lee ( $\nabla$ kleeklee@gmail.com )

Queen Mary Hospital https://orcid.org/0000-0003-4138-8219

Kar Kin Albert Chung

University of Hong Kong

\section{Research article}

Keywords: HIV, gay or bisexual men, methamphetamine, chemsex, Axis I psychiatric disorders, psychotropic substance

Posted Date: June 18th, 2020

DOI: https://doi.org/10.21203/rs.3.rs-32269/v1

License: (c) (i) This work is licensed under a Creative Commons Attribution 4.0 International License. Read Full License 


\section{Abstract}

Background: Psychotropic substance use is common in HIV-infected gay or bisexual men (GBM). This study examined the association between Axis I psychiatric disorders and active psychotropic substance use, and identified factors affecting the prevalence of psychiatric disorders in HIV-infected GBM.

Methods: This is a cross-sectional case-control study taken place in an HIV clinic and community organisations serving people living with HIV or GBM in Hong Kong. Participants were 62 HIV-infected self-identified GBM who reported psychotropic substance use in the past 1 year (cases), and 55 HIV-infected self-identified GBM without psychotropic substance use in the past 1 year and had negative toxicology tests at recruitment (controls).

The Chinese-bilingual Structured Clinical Interview for DSM-IV (Axis I, Patient version) was followed to establish the psychiatric diagnoses. Socio-demographic data, level of social support, HIV-related data, and pattern of psychotropic substance use were collected.

Results: Cases had lower level of social support ( $p=0.02$ ), more depressive disorders (AOR 3.4, 95\% CI 1.3-8.7, $p=0.01$ ) and psychotic disorders (AOR 7.2, 95\% CI 1.2-41, $p=0.03$ ) but not anxiety disorders. Significant difference in the prevalence of psychiatric disorders was only evident for disorders with onset after HIV diagnosis. Methamphetamine dependence (AOR 6.63, 95\% Cl 1.53-228.72, $p<0.01$ ), weekly methamphetamine use for 2 years or more (AOR 18.6, 95\% Cl 1.26-274.69, $p=0.03$ ), using methamphetamine beyond chemsex (AOR 4.76, 95\% $\mathrm{Cl} 1.17-19.41, p=0.03$ ) were significant predictors for psychiatric disorders in the cases in separate logistic regression models. Duration of HIV diagnosis was a significant independent predictor in all three models.

Conclusions: Active psychotropic substance use in HIV-infected gay or bisexual men was associated with a 3-fold increase in Axis I psychiatric disorders. This increase in psychiatric disorders was predicted by the severity, duration and context of methamphetamine use and the duration of HIV diagnosis.

\section{Background}

Psychotropic substance (PS) use is highly common in HIV-infected gay or bisexual men (GBM) with reported prevalence ranging from $30-60 \%$ over a 3- to 12-month period (1-4). Recently the pattern of PS use has shifted from with the predominate use of 'club drugs' such as 3,4-methylenedioxymethamphetmine (MDMA) and ketamine for socializing or dancing $(5,6)$ to methamphetamine and $g$-hydroxybutyrate $(\mathrm{GHB})$ for enhancing their sexual experiences $(7,8)$. The latter phenomenon is now commonly known as 'chemsex' (9).

The use of PS has been shown to associate with higher risks of psychiatric disorders. Methamphetamine users were 11 times more likely to have psychosis than the general population (10) and that the intensity, defined as the product the of frequency and duration of methamphetamine use, was associated with more depressive symptoms (11). Frequent cannabis use was associated with elevated risks of schizophrenia $(12,13)$ and depression (14). The positive relationship between substance use disorder (SUD) and Axis I psychiatric disorders has been confirmed by decades of epidemiological studies and a meta-analysis (15). The risks for various psychiatric disorders were different for different PS (16).

As the sexual minority and living with HIV infection both increased the risks of having psychiatric disorders (17-20). Factors related to higher psychiatric morbidities in people living with HIV (PLHIV) included low nadir CD4 (21), symptomatic infections $(22)$, co-occurring HCV infection $(21,23)$ and absence or non-adherence of antiretroviral treatment (ART) $(22,24-26)$. It is uncertain how the pattern of PS use among HIV-infected GBM associates with the profile of psychiatric disorders in this highly-stigmatised population. 
In Hong Kong, a special administrative region in the southern part of China, a HIV epidemic in GBM was observed in the past decade (27). At the largest local HIV clinic, the proportion of new attendees with homosexually acquired HIV reported ever methamphetamine use increased from 24\% in 2014 to 36\% in 2016 (Chan K. Personal Communication. 7 June 2017). The earlier local studies of psychiatric aspect of PLHIV fell short of focusing in this sexual minority group (28) without examining the relationships between substance use and psychiatric disorders (29). There has been no published study using standard diagnostic tools on psychiatric and substance use disorders of HIV-infected GBM in Asian settings.

\section{Methods}

\section{Aim}

This study aimed to determine the association between Axis I psychiatric disorders and active PS use, and to identify the socio-demographic, HIV-related and substance-related factors affecting the prevalence of Axis I psychiatric disorders in HIV-infected GBM.

\section{Study design}

This was a cross-sectional case-control study.

\section{Study settings}

Subjects were recruited from Integrated Treatment Centre (ITC) and eight community non-governmental organisations (NGO) that provide HIV services to GBM or support services to PLHIV. ITC is the largest clinic serving $70 \%$ of local HIV infection caseloads (30).

\section{Participants}

Inclusion criteria were self-identified GBM diagnosed with HIV infection for 1 month or more. Cases were those reported any PS use in the previous 1 year. Controls were those reported no PS use in the previous 1 year with a negative urine toxicology screening result at the time of recruitment. Never PS use was uncommon in this population thus a one-year cutoff was chosen to differentiate the cases from the controls according to the symptoms duration required for diagnosing substance related disorders in DSM-IV. A one-month period from initial HIV diagnosis to recruitment allowed observation of any psychiatric symptoms emerged and persisted to fulfil any diagnostic criteria. HIV status was confirmed for those receiving HIV treatment from ITC or having two different HIV antibody tests tested positive. Those could not communicate in Chinese or English, could not provide an informed consent, aged below 16 or did not usually reside locally $(<50 \%$ time in previous or coming 6 months) were excluded.

\section{Study variables}

\section{Axis I psychiatric diagnosis}

The modules on mood disorders, anxiety disorders, psychotic disorders and substance related disorders of the ChineseBilingual Structured Interview for the Diagnostic and Statistical Manual of Mental Disorders, Fourth Edition (Axis I, Patient version) (CB-SCID-I/P) were followed to establish the current and lifetime psychiatric diagnosis. CB-SCID-I/P has been validated locally $(31,32)$ and is currently the most updated translated Chinese version available. 


\section{Pattern and severity of psychotropic substance use}

The types and methods of PS use, its use in chemsex or other settings, frequency of use in past 1 year and days of use in the past 1 month were obtained.

\section{Socio-demographic data and social support}

Age, ethnicity, education attainment, relationship status, employment status, income level and living arrangement were collected by self-administered survey. Level of social support was measured by the Medical Outcomes Study Social Support Survey (MOS-SSS). It is a 19-item self-administered questionnaire that examined 4 domains of social support, including tangible support (TAN), affectionate support (AFF), positive social interaction (POS) and emotional or informational support (EMI) (33). This has been validated in Hong Kong Chinese (34) and has been used in a local study of PLHIV (35).

\section{HIV - related data}

Duration of HIV diagnosis, use of ART and adherence were collected by interviewer-administered questionnaire. The most recent CD4, HIV viral load (VL), hepatitis C (HCV) co-infection, and stage of HIV infection were obtained from the clinical system of ITC or from the blood samples collected at study recruitment. The definitions are shown in Table 1.

\section{Study administration}

Convenience sampling was used. Staff at the study sites invited potentially eligible subjects to contact the research coordinator who screened for their eligibility and arranged the interviews. The authors conducted the interviews in private rooms in ITC or the NGO. Subjects completed a questionnaire on demography, HIV-related data and MOS-SSS, followed by the assessment of PS use pattern and ascertainment of psychiatric diagnosis. Urine toxicology screening was performed by commercially available kits (Wondfo®) for the presence of amphetamines, barbituates, benzodiazepines, cocaine, marijuana, methamphetamine, MDMA, morphine, opiate, ketamine and synthetic cannabis. Subjects provided their unique clinic number and date of birth for data retrieval from ITC or provided blood samples for laboratory investigations. Subjects were referred to various treatment agencies when appropriate with their consent.

\section{Sample size calculations and statistical analysis}

Referenced from Bing et al. (2001), the cases were assumed to be 3 times more likely to have any mood, anxiety or psychotic disorders. With a $20 \%$ lifetime prevalence of psychiatric disorders (excluding substance related disorders) in the controls, $80 \%$ power and $5 \%$ Type I error, subjects required in each arm was estimated to be 60 .

Odds ratios were calculated to compare the differences in psychiatric diagnoses between the cases and controls. Adjustments for potential confounding factors identified in univariate analysis were performed using multiple logistic regression. Univariate and multivariate analyses using logistic regressions were performed to identify factors affecting the prevalence of psychiatric diagnosis (excluding substance related disorders) in the cases and controls. Following earlier recommendations $(36,37)$, no adjustments were made for multiple comparison as selection of the factors under studied were informed by previous research. In this relatively small study, this would also avoid reduction in power thus missing possible significant findings for further investigations. All comparisons of CD4 counts were age and ethnicity-adjusted. All statistical analyses were performed using SPSS version 24.0 using two-sided tests and a $p$-value $<0.05$ was considered statistically significant. 


\section{Results \\ Subjects' description}

During September 2017 to May 2018, 117 subjects were recruited. Their background characteristics are shown in Table 2. The cases scored significantly lower in the total and subscales of MOS-SSS except tangible support subscale. The cases had higher rate of HIV non-suppression after ART than the controls although the difference was statistically insignificant

(Fisher exact test, $p=0.06$ ). The cases were comparable to the controls in terms of other demographic variables and stage of HIV infection. The subjects recruited from ITC and NGO were comparable except all non-Chinese subjects came from ITC (Fisher exact test, $p=0.006)$.

Psychotropic substance use pattern Table 3 lists the specific types and number of PS used by the cases and controls. Methamphetamine was the most commonly used PS: $97 \%$ of the cases and $13 \%$ of the controls reported ever used. Onethird of the controls reported previous PS use.

Table 4 details the methamphetamine use pattern in the cases. A quarter started methamphetamine use after HIV diagnosis and $55 \%$ of those started methamphetamine use before HIV diagnosis did not reduce the frequency of use afterwards. Only $3 \%$ reported regular injections. Methamphetamine use for sex i.e. chemsex, was highly common: $87 \%$ initiated and 95\% ever used methamphetamine at chemsex. Methamphetamine was also the most frequently used PS with $22 \%$ using it for more than 14 days in the previous month, a frequency only reported by 2 cases for GHB and none for other substances (Supplementary data Table S1).

\section{Pattern of DSM-IV Axis I psychiatric diagnosis}

Table 5 and Table 6 list the lifetime and current SUD and other psychiatric diagnoses according to the DSM-IV criteria. Methamphetamine-related SUD was the most common SUD in the cases: $50 \%(n=31)$ fulfilled criteria for DSM-IV lifetime methamphetamine dependence and $8 \%(n=5)$ methamphetamine abuse. Depressive disorders were the most common diagnoses across all subjects, followed by psychotic disorders. Figure 1 illustrates the pattern of co-occurring psychiatric diagnoses in the cases and controls.

After adjustments with age, duration of HIV diagnosis and level of social support, cases were 6.1 times $(95 \% \mathrm{Cl} 2.5-14.8$, $p<0.001)$ more likely to have lifetime psychiatric diagnosis and 3.1 times $(95 \% \mathrm{Cl} 1.3-7.6, p<0.001)$ more likely to have lifetime psychiatric diagnosis excluding SUD (Table 7). Specifically, they were 7.2 times $(95 \% \mathrm{Cl} 1.3-41, p=0.03)$ more likely to have lifetime psychotic disorders and 3.4 times $(95 \% \mathrm{Cl} 1.3-8.7, p=0.01)$ more likely to have lifetime depressive disorders. After excluding substance-induced depressive episodes, cases were still 2.7 times $(95 \% \mathrm{Cl} 1.0-6.9, p=0.04)$ more likely to have lifetime depressive disorders. The prevalence of lifetime anxiety disorders in the case and controls did not differ significantly (adjusted OR 1.1, 95\% Cl 0.3-4.7, $p=0.86$ ).

There was no statistical difference was observed in the prevalence of psychiatric disorders with onset prior to HIV diagnosis between the cases and controls, but the cases were 6 times (AOR 6.36, 95\% Cl 1.96-20.65, $p=0.002$ ) more likely to have any psychiatric disorders with onset after HIV diagnosis (Table 8).

\section{Factors affecting the prevalence of DSM-IV Axis I psychiatric diagnosis}

Table 9 shows the univariate analysis of factors affecting the prevalence of lifetime psychiatric disorders in the cases. Methamphetamine dependence was highly correlated with SUD, $r(62)=0.822$. $p<0.01$ and duration of weekly use of 
methamphetamine, $r(62)=0.769, p<0.01$ (Supplementary data Table S2). Multivariate analyses excluding these highlycorrelated variables were performed separately (Table 10). In the first two models, either methamphetamine dependence (AOR 6.63, 95\% Cl 1.53-28.72, $p=0.01$ ) or SUD (AOR 6.80, 95\% Cl 1.38-33.62, $p=0.02$ ) and duration of HIV diagnosis remained as significant predictors. In the third model which excluded methamphetamine dependence and SUD from the analysis, methamphetamine use beyond chemsex (AOR 4.76, 95\% $\mathrm{Cl} 1.17-19.41, p=0.03$ ) and duration of HIV diagnosis remained as independent predictors. As methamphetamine use beyond chemsex was moderately correlated with methamphetamine dependence, $r(60)=0.533, p<0.01$ and weakly correlated with duration of weekly methamphetamine use, $r(60)=0.464, p<0.01$, a fourth model was built excluding methamphetamine dependence, methamphetamine use beyond chemsex and SUD. In this model, having weekly use of methamphetamine for 2 years or more (AOR $18.60,95 \% \mathrm{Cl}$ 1.26-274.69, $p=0.03$ ) and duration of HIV diagnosis remained as independent predictors. All models showed satisfactory goodness-of-fit.

Multivariate analysis in the controls showed that SUD (AOR 17.51, 95\% CI 1.42-300, $p=0.03$ ) and family history of mental illness (AOR 6.25, 95\% Cl 1.51-25.82, $p=0.01$ ) were independent significant predictors in the final model (Supplementary data Table S3-4).

\section{Discussion}

Our sample was characterised by relatively young age, more recent HIV diagnosis, low level of virological or immunological failure and a distinct PS use pattern. These were consistent with other local reports $(29,38,39)$ and contrasted with overseas cohorts that often consisted of men of older age with less favourable HIV outcomes $(2,40)$. Methamphetamine was the most commonly and frequently used substance, unlike the more prevalent use of cannabis or cocaine elsewhere. IDU rate was of the lower range compared to studies from the UK and Australia $(2,4)$.

Methamphetamine users in our study had less frequent, less injection and shorter duration of methamphetamine use compared to overseas cohorts whose sexual orientation or HIV status were unspecified $(10,41,42)$.

Consistent with literature, depressive disorders were the most common psychiatric diagnosis in our sample. The risk of lifetime depressive disorders in our cases (AOR 3.40,95\% $\mathrm{Cl} 1.33-8.69, p=0.01$ ) was different from the lack of significant association of depression with methamphetamine use, slightly stronger than that with cocaine use and was comparable to that with drug abuse reported by Skeer, Mimiaga (40). Although comparison of their cross-sectional measures with our lifetime diagnosis is difficult, the difference observed could be related to their use of PHQ-9 which is less specific than the standard diagnosing tool and the inclusion of active users of other PS in the comparison group hence weakening their associations. It may also be explained by the more severe substance use in our sample: $52 \%$ of our cases fulfilled DSM-IV dependence criteria, whereas Skeer, Mimiaga (40) reported in their study that 55\% of their substance users fulfilled the less restrictive abuse criteria using PHQ. The lack of description of methamphetamine use pattern by Forrest, Metsch (43) rendered comparisons to their results difficult.

The rate of lifetime psychotic disorders in our cases was comparable to other studies $(10,44)$ despite different assessment methods were used in samples with heavier and longer methamphetamine use. The proportion of lifetime methamphetamine-induced psychotic disorder among subjects with methamphetamine dependence (32\%) resembled previous findings $(10,45,46)$. The lack of schizophrenia was likely related to our small sample size with less frequent and shorter duration of methamphetamine use, based on the conversion rate reported by Niemi-Pynttari, Sund (47).

The lack of significant association of anxiety disorders with PS use observed in our study was similarly reported by Skeer et al. (2012). As homelessness, HIV symptoms and IDU predicted the anxiety level in PLHIV $(48,49)$, the absence of homelessness, few IDU and immunological failure in our cases may explain the low prevalence of anxiety disorder observed. 
Corroborated with previous research $(10,11,41)$, methamphetamine dependence and duration of methamphetamine use significantly predicted lifetime psychiatric disorders in our cases. The difference in rates of psychotic disorders as reported by McKetin, McLaren (10) could be related to different outcome measures. The infrequent and short duration of methamphetamine use in our non-dependent cases could also have inflated our odds ratio (Supplementary data Table S5). We showed that weekly use of methamphetamine for 2 years or more significantly predicted psychiatric disorders, concurred with previous findings on the positive relationship between frequency and duration of methamphetamine use and psychotic symptoms $(10,44)$.

A prominent finding from this study was the positive association between active PS use and psychiatric disorders appeared only for those with onset after HIV diagnosis. Our findings showed that weekly methamphetamine use of more than 2 years, methamphetamine use beyond chemsex and methamphetamine dependence predicted psychiatric disorders, and that all these factors correlated with a report of initiating or increasing methamphetamine use after HIV diagnosis. These observations suggested the diagnosis of HIV may have a critical impact in influencing the pattern of PS use and psychiatric diagnosis, although the characteristics of such relationships such as causality and temporality needs further evaluation.

This postulation concurred with earlier studies showing methamphetamine use was associated with the purpose to avoid unpleasant emotions in mixed-HIV status GBM (50) and to deal with negative emotions associated with HIV (51-53). Low mood was a major reason for PS use in local HIV-infected drug users, majority of whom were MSM (29). Our findings extended this knowledgebase and illustrated that using methamphetamine at non-sexual settings correlated with methamphetamine dependence and duration of HIV diagnosis and predicted psychiatric disorders. To avoid ongoing HIV transmissions, instead of using methamphetamine in chemsex which commonly took place over weekends, some cases reported using methamphetamine at other situations such as masturbation that could happen more frequently. This shift in the setting of methamphetamine use was probably unique in GBM, as chemsex with methamphetamine was much less common in the general population $(54,55)$.

The finding that the duration of HIV diagnosis predicated psychiatric diagnosis echoed previous results $(56,57)$ although direct comparison between the lifetime diagnosis and the point prevalence used in the other studies was difficult. The lack of significant association of psychiatric disorders with the stage of HIV infection echoed previous findings $(21,58,59)$.

To our knowledge, this is the first study that examined PS use and its relationship with psychiatric disorders in HIVinfected GBM using a standard diagnostic tool. The incorporation of socio-demographic, HIV-related and substancerelated factors in examining psychiatric epidemiology generated new insights into the possible inter-relationships among them. A case-control study design was more efficient than a prevalence survey and it minimised the sampling and surveillance bias when the cases and controls were compared. Multiple recruitment sources allowed sampling of subjects not engaged in HIV treatment during the study period, a situation more common among those with active PS use. The close collaborations with NGOs provided flexibility in scheduling the interviews at locations familiar and convenient to the subjects, facilitating recruitment of this hard-to-reach group. The inclusion of psychotic disorders filled a research gap that is relevant to the common use of methamphetamine in this population. The use of laboratory and clinical markers minimised recall bias.

This study had several limitations. Firstly, there was selection bias in non-randomised samples that limited the generalisability of our results. Our cases were largely comparable to the sample reported by Lee, Chan (29) regarding the proportion of viral suppression and living alone, although they were older with lower CD4 level. This could be explained by the discrepancy in case-mix where the hospital-based clinics were more likely providing care for patients with more severe disease, the minority of heterosexual subjects sampled and the lower CD4 observed with ageing. The lack of local data on PS use pattern in this population made assessment of the representativeness regarding these aspects difficult. Individuals with more severe PS use might not have joined the study, like when the substance use took priority. Sampling at the NGOs 
where free HIV testing services were provided might have resulted in sampling of subjects with relatively short duration of methamphetamine use. It is uncertain if our subjects joined the study for treatment leading to over-estimation of the prevalence of psychiatric disorders. Yet even if these exist, the comparisons between the cases and the controls should still be valid. Secondly, the results of this study could not indicate any causal relationships between the factors studied as our study was not powered to detect the differences in specific psychiatric diagnosis. Thirdly, there could be recall bias in substance use patterns, past psychiatric symptoms and ART adherence.

\section{Conclusion}

Active PS use in HIV-infected GBM was associated with a three-fold increase in psychiatric disorders. The increase was evident only for those with onset after HIV diagnosis and was predicted by the severity, duration and context of methamphetamine use and duration of HIV diagnosis. These findings supported regular screening of depression and PS use in HIV clinical care. The predictors for psychiatric disorders should be further explored as potentially effective harm reduction measures. With the continued HIV epidemic in GBM and the popularity of methamphetamine in Asia, a proportion of these highly-stigmatised individuals suffered multiple biopsychosocial disadvantages despite the availability of highly effective HIV treatment. Chemsex, a less described phenomenon in this region, has been the most important context where they explored and continued their methamphetamine use. Coordinated efforts from HIV, psychiatric and substance use services are needed to prevent harms arising from PS use and chemsex and to identify those in need and facilitate treatment access.

\section{Declarations}

\section{Ethics approval and consent to participate}

Approval by the Institutional Review Board of the University of Hong Kong/Hospital Authority Hong Kong West Cluster, Queen Mary Hospital (IRB reference number UW 16-406 and UW 18-387) and the Ethics Committees of the Department of Health, Hong Kong SAR Government (LM 366/2016) were obtained. Written informed consent was obtained from each participant before the study.

\section{Consent for publication}

Not applicable.

Availability of data and materials

The datasets generated and analysed during the current study are not publicly available due to sensitivity of the research questions but are available from the corresponding author on reasonable request.

Competing interests

The authors declare that they have no competing interests.

Funding

LCK received a grant from Training and Research Sponsorship Scheme of the Queen Mary Hospital for this study. The funders had no role in study design, data collection and analysis, decision to publish, or preparation of the manuscript.

\section{Authors' contributions}


LCK and CKK conceptualised the study and collected the data. LCK analyzed and interpreted the patient data and draft the manuscript. All authors read and approved the final manuscript.

\section{Acknowledgements}

The authors were indebted to Professor LEE Shui-shan, Dr. WONG Ka-hing and Dr. CHAN Chi-wai Kenny and the nursing staff of ITC for giving tremendous support to allow the study to be conducted at ITC. The sincerest appreciation goes to all colleagues of the participating community organisations, including A-backup, AIDS Concern, CHOICE, Chem sex support service, Heart to Heart, Hong Kong AIDS Foundation, Rainbow of Hong Kong and Poz Positive, for their extraordinary efforts in subjects' recruitment and provision of interview venues. The authors were also grateful to Dr. WONG Ming-cheuk Michael for his support and guidance throughout the research, Professor MAK Winnie Wing-sze for her permission to use the Chinese version of MOS-SSS and the Stanley Ho Centre for Emerging Infectious Diseases of the Chinese University of Hong Kong for laboratory support. The greatest gratitude goes to all the participants for their contribution to the research.

\section{Abbreviations}

AFF: affectionate support

CB-SCID-I/P: Chinese-Bilingual Structured Interview for the Diagnostic and Statistical Manual of Mental Disorders, Fourth Edition (Axis I, Patient version)

EMI: and emotional or informational support

GBM: gay or bisexual men

GHB: $g$-hydroxybutyrate

HCV: hepatitis C

ITC: Integrated Treatment Centre

MDMA: 3,4-methylenedioxymethamphetmine

MOS-SSS: Medical Outcomes Study Social Support Survey

NGO: non-governmental organisations

PLHIV: people living with HIV

POS: positive social interaction

PS: Psychotropic substance

SUD: substance use disorder

TAN: tangible support

VL: viral load

\section{References}


1. Center for Disease Control and Prevention. HIV Infection Risk, Prevention, and Testing Behaviors among Men Who Have Sex With Men-National HIV Behavioral Surveillance, 20 U.S. Cities, 2014. HIV Surveillance Special Report 15. 2016.

2. Daskalopoulou M, Rodger A, Phillips AN, Sherr L, Speakman A, Collins S, et al. Recreational drug use, polydrug use, and sexual behaviour in HIV-diagnosed men who have sex with men in the UK: results from the cross-sectional ASTRA study. Lancet HIV. 2014;1(1):e22-31.

3. Wei C, Guadamuz TE, Lim SH, Huang Y, Koe S. Patterns and levels of illicit drug use among men who have sex with men in Asia. Drug Alcohol Depend. 2012;120(1-3):246-9.

4. Lee E, Mao L, Broady T, Bavinton B, McKenzie T, Batrouney C, et al. Gay community periodic survey: Melbourne 2018. Syndey, Australia: Centre for Social Research in Health, UNSW 2018.

5. Halkitis PN, Parsons JT. Recreational drug use and HIV-risk sexual behavior among men frequenting gay social venues. J Gay Les Soc Serv. 2002;14(4):19-38.

6. Halkitis PN, Palamar JJ. Multivariate modeling of club drug use initiation among gay and bisexual men. Subst Use Misuse. 2008;43(7):871-9.

7. Hurley M, Prestage G. Intensive sex partying amongst gay men in Sydney. Cult Health Sex. 2009;11(6):597-610.

8. Ross MW, Mattison AM, Franklin DR, Jr. Club drugs and sex on drugs are associated with different motivations for gay circuit party attendance in men. Subst Use Misuse. 2003;38(8):1173-83.

9. Bourne A, Reid D, Hickson F, Torres-Rueda S, Weatherburn P. Illicit drug use in sexual settings ('chemsex') and HIV/STI transmission risk behaviour among gay men in South London: findings from a qualitative study. Sex Transm Infect. 2015;91(8):564-8.

10. McKetin R, McLaren J, Lubman DI, Hides L. The prevalence of psychotic symptoms among methamphetamine users. Addiction. 2006;101(10):1473-8.

11. Semple SJ, Patterson TL, Rant I. Methamphetamine use and depressive symptoms among heterosexual men and women. J Subst Use. 2005;10(1):31-47.

12. Zammit S, Allebeck P, Andreasson S, Lundberg I, Lewis G. Self reported cannabis use as a risk factor for schizophrenia in Swedish conscripts of 1969: historical cohort study. BMJ. 2002;325(7374):1199.

13. Moore THM, Zammit S, Lingford-Hughes A, Barnes TR, Jones PB, Burke M, et al. Cannabis use and risk of psychotic or affective mental health outcomes: a systematic review. The Lancet. 2007;370(9584):319-28.

14. Lev-Ran S, Roerecke M, Le Foll B, George TP, McKenzie K, Rehm J. The association between cannabis use and depression: a systematic review and meta-analysis of longitudinal studies. Psychol Med. 2014;44(4):797-810.

15. Lai HM, Cleary M, Sitharthan T, Hunt GE. Prevalence of comorbid substance use, anxiety and mood disorders in epidemiological surveys, 1990-2014: A systematic review and meta-analysis. Drug Alcohol Depend. 2015;154:1-13.

16. Regier DA, Farmer ME, Rae DS, Locke BZ, Keith SJ, Judd LL, et al. Comorbidity of mental disorders with alcohol and other drug abuse. Results from the Epidemiologic Catchment Area (ECA) Study. JAMA. 1990;264(19):2511-8.

17. King M, Semlyen J, Tai SS, Killaspy H, Osborn D, Popelyuk D, et al. A systematic review of mental disorder, suicide, and deliberate self harm in lesbian, gay and bisexual people. BMC Psychiatry. 2008;8:70.

18. Meyer IH. Prejudice, social stress, and mental health in lesbian, gay, and bisexual populations: conceptual issues and research evidence. Psychol Bull. 2003;129(5):674-97.

19. Ciesla JA, Roberts JE. Meta-analysis of the relationship between HIV infection and risk for depressive disorders. Am J Psychiatry. 2001;158(5):725-30.

20. Jallow A, Ljunggren G, Wändell P, Wahlström L, Carlsson AC. HIV-infection and psychiatric illnesses - A double edged sword that threatens the vision of a contained epidemic: The Greater Stockholm HIV Cohort Study. J Infect. 2017;74(1):22-8. 
21. Anagnostopoulos A, Ledergerber B, Jaccard R, Shaw SA, Stoeckle M, Bernasconi E, et al. Frequency of and risk factors for depression among participants in the Swiss HIV cohort study (SHCS). PLoS One. 2015;10(10):e0140943.

22. Gaynes BN, Pence BW, Eron JJ, Miller WC. Prevalence and comorbidity of psychiatric diagnoses based on reference standard in an HIV+ patient population. Psychosom Med. 2008;70(4):505-11.

23. Atkinson JH, Heaton RK, Patterson TL, Wolfson T, Deutsch R, Brown SJ, et al. Two-year prospective study of major depressive disorder in HIV-infected men. J Affect Disord. 2008;108(3):225-34.

24. Gonzalez JS, Batchelder AW, Psaros C, Safren SA. Depression and HIV/AIDS treatment nonadherence: a review and meta-analysis. Journal of acquired immune deficiency syndromes (1999). 2011;58(2):181-7.

25. Gutierrez F, Garcia L, Padilla S, Alvarez D, Moreno S, Navarro G, et al. Risk of clinically significant depression in HIVinfected patients: effect of antiretroviral drugs. HIV medicine. 2014;15(4):213-23.

26. Helleberg M, Pedersen MG, Pedersen CB, Mortensen PB, Obel N. Associations between HIV and schizophrenia and their effect on HIV treatment outcomes: a nationwide population-based cohort study in Denmark. Lancet HIV. 2015;2(8):e344-e50.

27. Special Preventive Programme. HIV Surveillance Report - 2016 Update. In: Special Preventive Programme CfHP, Department of Health, editor. Hong Kong: Surveillance Team, Special Preventive Programme, Centre for Health Protection, Department of Health, Hong Kong Special Administrative Region; 2017.

28. Au A, Cheng C, Chan I, Leung P, Li P, Heaton RK. Subjective memory complaints, mood, and memory deficits among HIV/AIDS patients in Hong Kong. J Clin Exp Neuropsychol. 2008;30(3):338-48.

29. Lee MP, Chan ML, Chan YT, Chan SN, Yu P, Chung WY, et al. Survey on drug use among people living with HIV in Hong Kong. Int J Ment Health Addict. 2018:1-10.

30. Wong NS, Wong KH, Wong PKH, Lee SS. Incorporation of estimated community viral load before HIV diagnosis for enhancing epidemiologic investigations: a comparison between men who have sex with men and heterosexual men in Hong Kong. Asia Pac J Public Health. 2015;27(7):756-64.

31. So E, Kam I, Lam L. The Chinese-bilingual SCID-I/P project: stage 3 - multi-site inter-rater reliability. Hong Kong J Psychiatry. 2004;1:19-25.

32. So E, Kam I, Leung CM, Chung D, Liu Z, Fong S. The Chinese- bilingual SCID-I/P project: stage 1 - reliability for mood disorders and schizophrenia. Hong Kong J Psychiatry 2003;13:7-18.

33. Sherbourne CD, Stewart AL. The MOS social support survey. Soc Sci Med. 1991;32(6):705-14.

34. Yu DS, Lee DT, Woo J. Psychometric testing of the Chinese version of the medical outcomes study social support survey (MOS-SSS-C). Research in nursing \& health. 2004;27(2):135-43.

35. Mak WW, Cheung RY, Law RW, Woo J, Li PC, Chung RW. Examining attribution model of self-stigma on social support and psychological well-being among people with HIV+/AIDS. Soc Sci Med. 2007;64(8):1549-59.

36. Feise RJ. Do multiple outcome measures require p-value adjustment? BMC Med Res Methodol. 2002;2:8-.

37. Rothman KJ. No adjustments are needed for multiple comparisons. Epidemiology. 1990;1(1):43-6.

38. Kwan TH, Poon CM, Wong KH, Lee SS. Effects of HIV diagnosis and enrolment in care on transmission risk of HIVinfected men who have sex with men in Hong Kong: a cross-sectional study. Lancet. 2016;388:48-.

39. Hong Kong Advisory Council on AIDS. Recommended HIV/AIDS Strategies for Hong Kong (2017-2021). 2017.

40. Skeer MR, Mimiaga MJ, Mayer KH, O'Cleirigh C, Covahey C, Safren SA. Patterns of substance use among a large urban cohort of HIV-infected men who have sex with men in primary care. AIDS Behav. 2012;16(3):676-89.

41. Ma J, Li X-D, Wang T-Y, Li S-X, Meng S-Q, Blow FC, et al. Relationship between the duration of methamphetamine use and psychotic symptoms: A two-year prospective cohort study. Drug Alcohol Depend. 2018;187:363-9.

42. McKetin R, Dawe S, Burns RA, Hides L, Kavanagh DJ, Teesson M, et al. The profile of psychiatric symptoms exacerbated by methamphetamine use. Drug Alcohol Depend. 2016;161:104-9.

Page $11 / 23$ 
43. Forrest DW, Metsch LR, LaLota M, Cardenas G, Beck DW, Jeanty Y. Crystal methamphetamine use and sexual risk behaviors among HIV-positive and HIV-negative men who have sex with men in South Florida. J Urban Health. 2010;87(3):480-5.

44. Ma J, Sun X-J, Wang R-J, Wang T-Y, Su M-F, Liu M-X, et al. Profile of psychiatric symptoms in methamphetamine users in China: Greater risk of psychiatric symptoms with a longer duration of use. Psychiatry Res. 2018;262:184-92.

45. Salo R, Flower K, Kielstein A, Leamon MH, Nordahl TE, Galloway GP. Psychiatric comorbidity in methamphetamine dependence. Psychiatry Res. 2011;186(2-3):356-61.

46. Shoptaw S, Peck J, Reback CJ, Rotheram-Fuller E. Psychiatric and substance dependence comorbidities, sexually transmitted diseases, and risk behaviors among methamphetamine-dependent gay and bisexual men seeking outpatient drug abuse treatment. J Psychoactive Drugs. 2003;35 Suppl 1:161-8.

47. Niemi-Pynttari JA, Sund R, Putkonen H, Vorma H, Wahlbeck K, Pirkola SP. Substance-induced psychoses converting into schizophrenia: a register-based study of 18,478 Finnish inpatient cases. J Clin Psychiatry. 2013;74(1):e94-9.

48. Ibañez GE, Purcell DW, Stall R, Parsons JT, Gómez CA. Sexual risk, substance use, and psychological distress in HIVpositive gay and bisexual men who also inject drugs. AIDS. 2005;19 Suppl 1:S49-55.

49. Semple SJ, Strathdee SA, Zians J, McQuaid J, Patterson TL. Psychosocial and behavioral correlates of anxiety symptoms in a sample of HIV-positive, methamphetamine-using men who have sex with men. AIDS Care. 2011;23(5):628-37.

50. Halkitis PN, Shrem MT. Psychological differences between binge and chronic methamphetamine using gay and bisexual men. Addict Behav. 2006;31(3):549-52.

51. Nakamura N, Semple SJ, Strathdee SA, Patterson TL. Methamphetamine initiation among HIV-positive gay and bisexual men. AIDS Care. 2009;21(9):1176-84.

52. Semple SJ, Patterson TL, Grant I. Motivations associated with methamphetamine use among HIV+ men who have sex with men. J Subst Abuse Treat. 2002;22(3):149-56.

53. Chartier M, Araneta A, Duca L, McGlynn LM, Gore-Felton C, Goldblum P, et al. Personal values and meaning in the use of methamphetamine among HIV-positive men who have sex with men. Qual Health Res. 2009;19(4):504-18.

54. Kerr T, Marshall BDL, Miller C, Shannon K, Zhang R, Montaner JSG, et al. Injection drug use among street-involved youth in a Canadian setting. BMC Public Health. 2009;9(1):171.

55. Sherman SG, German D, Sirirojn B, Thompson N, Aramrattana A, Celentano DD. Initiation of Methamphetamine Use Among Young Thai Drug Users: A Qualitative Study. Journal of Adolescent Health. 2008;42(1):36-42.

56. McGowan JA, Sherr L, Rodger AJ, Fisher M, Miners A, Anderson J, et al. Age, time living with diagnosed HIV infection, and self-rated health. HIV medicine. 2017;18(2):89-103.

57. Hammond ER, Lai S, Wright CM, Treisman GJ. Cocaine use may be associated with increased depression in persons infected with HIV. AIDS Behav. 2016;20(2):345-52.

58. Bing EG, Burnam MA, Longshore D, Fleishman JA, Sherbourne CD, London AS, et al. Psychiatric disorders and drug use among human immunodeficiency virus-infected adults in the United States. Arch Gen Psychiatry. 2001;58(8):7218.

59. Closson K, Osborne C, Smith DM, Kesselring S, Eyawo O, Card K, et al. Factors associated with mood disorder diagnosis among a population based cohort of men and women living with and without HIV in British Columbia between 1998 and 2012. AIDS Behav. 2018;22(5):1530-40.

60. Scientific Committee on AIDS. Classification system for HIV infection and surveillance case definition for AIDS among adolescents and adults in Hong Kong. In: AIDS HKACo, editor. Hong Kong1995.

61. European AIDS Clinical Society. Guidelines version 7.1. 2014. 
62. Ho CF, Fong OW, Wong KH. Patient self-report as a marker of adherence to antiretroviral therapy. Clinical infectious diseases : an official publication of the Infectious Diseases Society of America. 2002;34(11):1534-5.

63. Paterson DL, Swindells S, Mohr J, Brester M, Vergis EN, Squier C, et al. Adherence to protease inhibitor therapy and outcomes in patients with HIV infection. Ann Intern Med. 2000;133(1):21-30.

\section{Tables}

Table 1 Definitions of stage of HIV infection and HIV outcome measures

\begin{tabular}{|c|c|}
\hline Measures & Definitions \\
\hline $\begin{array}{l}\text { Stage of } H I V \\
\text { infection } 1\end{array}$ & $\begin{array}{l}\text { A - asymptomatic infection } \\
\text { B - symptomatic infection without AIDS-defining illness } \\
\text { C - symptomatic infection with AIDS-defining illness }\end{array}$ \\
\hline $\begin{array}{l}\text { Level of } \\
\text { immunodeficiency }\end{array}$ & $\begin{array}{l}1-\mathrm{CD} 4>499 / \mu \mathrm{L} \\
2-\mathrm{CD} 4200-499 / \mu \mathrm{L} \\
3-\mathrm{CD} 4<200 / \mu \mathrm{L}\end{array}$ \\
\hline $\begin{array}{l}\text { HIV non-suppression } \\
\text { \& virologic failure }\end{array}$ & $\begin{array}{l}\text { Any detectable HIV viral load defines HIV non-suppression; failure to achieve } \\
\text { undetectable HIV viral load } 6 \text { months after ART initiation defines virologic failure }\end{array}$ \\
\hline$A R T$ adherence 3 & $\begin{array}{l}\text { Number of doses taken over doses prescribed in the past } 3 \text { months; at least } 95 \% \text { was } \\
\text { considered satisfactory }\end{array}$ \\
\hline \multicolumn{2}{|c|}{$\begin{array}{l}\text { References: } \\
1 \text { Scientific Committee on AIDS (60) } \\
2 \text { European AIDS Clinical Society (61 } \\
3 \text { Ho, Fong (62), Paterson, Swindells }\end{array}$} \\
\hline
\end{tabular}

Table 2 Background characteristics of the subjects 


\begin{tabular}{|c|c|c|c|c|c|c|}
\hline \multirow{2}{*}{\multicolumn{2}{|c|}{ Socio-demographic characteristics }} & \multicolumn{2}{|c|}{ Case $(n=62)$} & \multicolumn{2}{|c|}{ Control $(n=55)$} & \multirow[t]{2}{*}{$p$-value ${ }^{1}$} \\
\hline & & & & & & \\
\hline \multicolumn{2}{|l|}{ Non-Chinese } & 5 & $8 \%$ & 3 & $6 \%$ & 0.72 \\
\hline \multicolumn{2}{|l|}{$\operatorname{Age}^{2}$} & 32 & {$[28,40]$} & 37 & {$[27,46]$} & 0.13 \\
\hline \multicolumn{2}{|l|}{ Bisexual } & 5 & $8 \%$ & 2 & $4 \%$ & 0.45 \\
\hline \multicolumn{2}{|c|}{ In a relationship/married } & 24 & $39 \%$ & 21 & $38 \%$ & 0.95 \\
\hline \multicolumn{2}{|l|}{ Lived alone } & 14 & $23 \%$ & 14 & $25 \%$ & 0.72 \\
\hline \multicolumn{2}{|l|}{ No tertiary education } & 16 & $26 \%$ & 20 & $36 \%$ & 0.21 \\
\hline \multirow[t]{3}{*}{ Occupation } & Part-time/unemployed & 19 & $31 \%$ & 11 & $20 \%$ & \multirow[t]{3}{*}{0.42} \\
\hline & Retired/student & 3 & $5 \%$ & 6 & $11 \%$ & \\
\hline & Full-time & 40 & $65 \%$ & 38 & $69 \%$ & \\
\hline \multirow[t]{3}{*}{ Monthly income } & $\$ 15000$ or below & 32 & $52 \%$ & 27 & $49 \%$ & \multirow[t]{3}{*}{0.67} \\
\hline & $\$ 15001-40000$ & 24 & $39 \%$ & 18 & $33 \%$ & \\
\hline & $\$ 40001$ or above & 6 & $10 \%$ & 10 & $18 \%$ & \\
\hline \multirow[t]{5}{*}{ Social support ${ }^{3,4}$} & MOS-SSS total & 59.8 & $(14.9)$ & 66.2 & $(15.1)$ & 0.02 \\
\hline & EMI subscale & 24.8 & $(7.3)$ & 27.6 & $(6.8)$ & 0.03 \\
\hline & AFF subscale & 9.5 & $(2.6)$ & 10.7 & $(2.5)$ & 0.02 \\
\hline & TAN subscale & 12.5 & $(4.2)$ & 13.0 & $(4.1)$ & 0.47 \\
\hline & POS subscale & 10.1 & $(3.0)$ & 11.5 & $(2.7)$ & 0.01 \\
\hline \multicolumn{7}{|c|}{ HIV-related characteristics } \\
\hline \multicolumn{2}{|c|}{ Duration of HIV diagnosis (year) ${ }^{2}$} & 2 & {$[0,6]$} & 2 & {$[1,7]$} & 0.13 \\
\hline \multirow[t]{3}{*}{ Stage of HIV infection } & A & 36 & $58 \%$ & 37 & $67 \%$ & \multirow[t]{2}{*}{0.36} \\
\hline & $\mathrm{B}$ or $\mathrm{C}$ & 8 & $10 \%$ & 13 & $24 \%$ & \\
\hline & Not available & 18 & $29 \%$ & 5 & $9 \%$ & \\
\hline \multicolumn{2}{|l|}{ Receiving ART } & 60 & $97 \%$ & 50 & $91 \%$ & 0.25 \\
\hline \multicolumn{2}{|l|}{ ART adherence <95\% } & $7 / 59$ & $12 \%$ & 1 & $2 \%$ & 0.07 \\
\hline \multicolumn{2}{|l|}{ HIV non-suppression ${ }^{5}$} & $7 / 56$ & $13 \%$ & $1 / 49$ & $2 \%$ & 0.06 \\
\hline \multicolumn{2}{|l|}{$\mathrm{CD} 4<200 \mu \mathrm{L}$} & $1 / 62$ & $2 \%$ & $2 / 53$ & $4 \%$ & 0.26 \\
\hline \multicolumn{2}{|l|}{ HCV co-infection } & $2 / 61$ & $3 \%$ & $0 / 53$ & $0 \%$ & 0.50 \\
\hline
\end{tabular}

1 t-test or Mann Whitney $U$ test for continuous variable, chi-square or fisher exact test for categorical variables, logistic regression was used to adjust for age and ethnicity in comparing CD4

2 median and inter-quartile ranges were presented

3 MOS-SSS medical outcome survey, social support scale, EMI emotional or informational support, AFF affectionate support, TAN tangible support, POS positive experiences

4 mean and standard deviations were presented

5 Excluding those received ART $<6$ months

Table 3 Types and numbers of psychotropic substance use in the cases and controls 


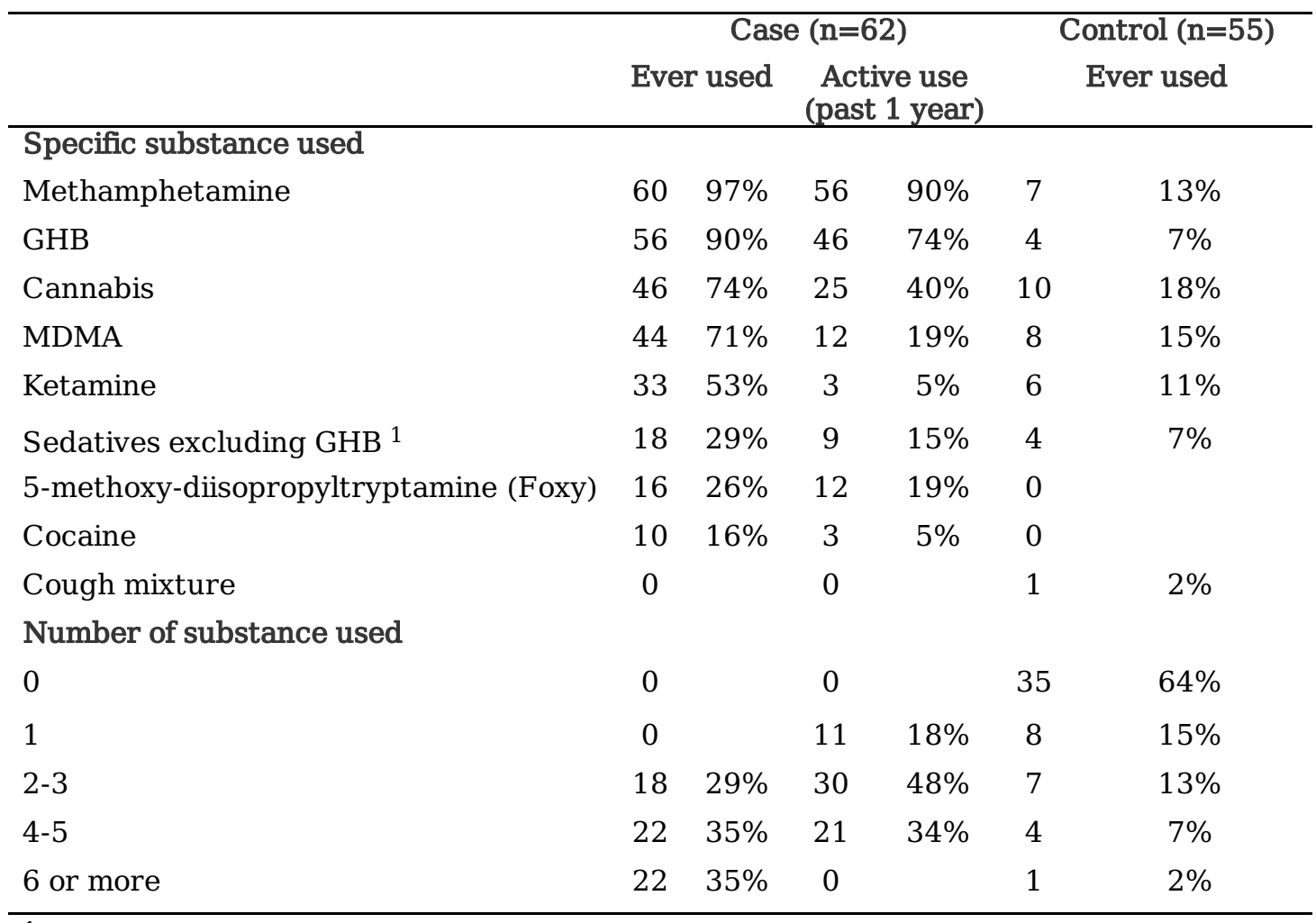

${ }^{1} 6$ of the 18 cases referred to nimetazepam (commonly known as 'five')

Table 4 Patterns of methamphetamine use in the cases 


\begin{tabular}{|c|c|c|c|}
\hline & & Cas & $(n=60)$ \\
\hline Age of first use ${ }^{1}$ & & 29 & $(22,35)$ \\
\hline Initiated use after HIV diagnosis & & 15 & $25 \%$ \\
\hline Frequency after HIV diagnosis & Stopped & 2 & $3 \%$ \\
\hline & Reduced & 13 & $22 \%$ \\
\hline & Similar & 10 & $17 \%$ \\
\hline & Increased & 15 & $25 \%$ \\
\hline & Not applicable (ever used once only) & 5 & $8 \%$ \\
\hline Intravenous use & Ever & 8 & $13 \%$ \\
\hline & Past 1 year & 7 & $12 \%$ \\
\hline & Regular intravenous use & 2 & $3 \%$ \\
\hline Use in chemsex & Initiated at chemsex & 52 & $87 \%$ \\
\hline & Ever used for chemsex & 57 & $95 \%$ \\
\hline & Exclusive use in chemsex only & 27 & $45 \%$ \\
\hline Duration of regular use (at least monthly) & Irregular use (less frequent than monthly) & 16 & $28 \%$ \\
\hline & 1 year or less & 17 & $30 \%$ \\
\hline & $>1$ year -2 years & 12 & $20 \%$ \\
\hline & $>2$ years -5 years & 9 & $15 \%$ \\
\hline & $>5$ years or more & 6 & $8 \%$ \\
\hline Duration of regular use (at least weekly) & Irregular use (less frequent than weekly) & 24 & $40 \%$ \\
\hline & 1 year or less & 17 & $30 \%$ \\
\hline & $>1$ year -2 years & 8 & $13 \%$ \\
\hline & $>2$ years -5 years & 8 & $13 \%$ \\
\hline & $>5$ years or more & 3 & $5 \%$ \\
\hline Days of use in the past 1 month & 0 & 24 & $40 \%$ \\
\hline & $1-2$ & 12 & $20 \%$ \\
\hline & $3-6$ & 7 & $12 \%$ \\
\hline & $7-14$ & 4 & $7 \%$ \\
\hline & 15 or more & 13 & $22 \%$ \\
\hline Estimated monthly cost & Free & 12 & $20 \%$ \\
\hline & HKD $\$ 1000$ or less & 11 & $18 \%$ \\
\hline & HKD\$1000-2000 & 7 & $12 \%$ \\
\hline & HKD $\$ 2000$ or more & 7 & $12 \%$ \\
\hline & Missing & 11 & $18 \%$ \\
\hline
\end{tabular}

Table 5 Lifetime and current DSM-IV substance use disorders in the cases and controls 


\begin{tabular}{|c|c|c|c|c|c|c|c|}
\hline & \multicolumn{4}{|c|}{ Lifetime diagnosis } & \multicolumn{3}{|c|}{ Current diagnosis } \\
\hline & \multicolumn{2}{|c|}{ Case $(n=62)$} & \multicolumn{2}{|c|}{ Control $(n=55)$} & \multicolumn{2}{|c|}{ Case $(n=62)$} & \multirow[t]{2}{*}{ Control $(n=55)$} \\
\hline \multicolumn{7}{|c|}{ Amphetamine-like substances related } & \\
\hline \multicolumn{8}{|c|}{ Methamphetamine-related } \\
\hline Abuse & 5 & $8 \%$ & 1 & $2 \%$ & 1 & $2 \%$ & 0 \\
\hline Dependence & 31 & $50 \%$ & 1 & $2 \%$ & 23 & $37 \%$ & 0 \\
\hline \multicolumn{8}{|c|}{ MDMA-related } \\
\hline Abuse & 0 & & 1 & $2 \%$ & 0 & & 0 \\
\hline Dependence & 1 & $2 \%$ & 1 & $2 \%$ & 0 & & 0 \\
\hline \multicolumn{8}{|c|}{ Cannabis-related } \\
\hline Abuse & 1 & $2 \%$ & 0 & & 1 & $2 \%$ & 0 \\
\hline Dependence & 1 & $2 \%$ & 0 & & 1 & $2 \%$ & 0 \\
\hline \multicolumn{8}{|c|}{ Hallucinogen-related (Ketamine) } \\
\hline Abuse & 0 & & 0 & & 0 & & 0 \\
\hline Dependence & 1 & $2 \%$ & 0 & & 0 & & 0 \\
\hline \multicolumn{8}{|c|}{ Sedatives-related } \\
\hline Abuse $^{1}$ & 2 & $3 \%$ & 0 & & 0 & & 0 \\
\hline Dependence $^{2}$ & 1 & $2 \%$ & 0 & & 1 & $2 \%$ & 0 \\
\hline \multicolumn{8}{|c|}{ Alcohol related } \\
\hline Abuse & 2 & $3 \%$ & & & 0 & & \\
\hline
\end{tabular}

${ }^{1}$ Both were GHB-related; ${ }^{2}$ Zopiclone-related

Table 6 Lifetime and current DSM-IV Axis I psychiatric diagnoses (excluding substance use disorders) in the cases and controls 


\begin{tabular}{|c|c|c|c|c|c|c|c|c|}
\hline \multirow[b]{3}{*}{ Any mood disorders } & \multicolumn{4}{|c|}{ Lifetime diagnosis } & \multicolumn{4}{|c|}{ Current diagnosis } \\
\hline & \multicolumn{2}{|c|}{$\begin{array}{l}\text { Case } \\
(n=62)\end{array}$} & \multicolumn{2}{|c|}{$\begin{array}{l}\text { Control } \\
(\mathrm{n}=55)\end{array}$} & \multicolumn{2}{|c|}{$\begin{array}{c}\text { Case } \\
(\mathrm{n}=62)\end{array}$} & \multicolumn{2}{|c|}{$\begin{array}{c}\text { Control } \\
(n=55)\end{array}$} \\
\hline & 25 & $40 \%$ & 10 & $18 \%$ & 9 & $15 \%$ & 2 & $4 \%$ \\
\hline Any depressive disorders & 25 & $40 \%$ & 9 & $16 \%$ & 9 & $15 \%$ & 2 & $4 \%$ \\
\hline Major depressive episode & 15 & $24 \%$ & 6 & $11 \%$ & 4 & $6 \%$ & 2 & $4 \%$ \\
\hline Single episode & 12 & $19 \%$ & 5 & $9 \%$ & 4 & $6 \%$ & 1 & $2 \%$ \\
\hline Recurrent & 3 & $5 \%$ & 1 & $2 \%$ & 0 & & 1 & $2 \%$ \\
\hline Depressive episode NOS & 5 & $8 \%$ & 3 & $5 \%$ & 1 & $2 \%$ & 0 & \\
\hline $\begin{array}{l}\text { Substance-induced mood disorder (with depressive } \\
\text { features) }\end{array}$ & 4 & $6 \%$ & 0 & & 3 & $5 \%$ & 0 & \\
\hline Dysthymia & 1 & $2 \%$ & 0 & & 1 & $2 \%$ & 0 & \\
\hline Bipolar disorders & 0 & & 1 & $2 \%$ & 0 & & 0 & \\
\hline Any anxiety disorders & 6 & $10 \%$ & 4 & $7 \%$ & 3 & $5 \%$ & 1 & $2 \%$ \\
\hline Agoraphobia & 0 & & 1 & $2 \%$ & 0 & & 0 & \\
\hline Panic disorder & 1 & $2 \%$ & 2 & $4 \%$ & 0 & & 0 & \\
\hline Social phobia & 3 & $5 \%$ & 0 & & 1 & $2 \%$ & 0 & \\
\hline PTSD $^{1}$ & 2 & $3 \%$ & 0 & & 0 & & 0 & \\
\hline Anxiety $\mathrm{NOS}^{2}$ & 3 & $5 \%$ & 1 & $2 \%$ & 2 & $3 \%$ & 1 & $2 \%$ \\
\hline Any psychotic disorders & 10 & $16 \%$ & 2 & $4 \%$ & 5 & $8 \%$ & 0 & \\
\hline Substance-induced & 10 & $16 \%$ & 1 & $2 \%$ & 5 & $8 \%$ & 0 & \\
\hline Brief psychotic disorder & 0 & & 1 & $2 \%$ & 0 & & 0 & \\
\hline
\end{tabular}

\footnotetext{
1 Post-traumatic stress disorders (PTSD)

2 not otherwise specified (NOS)
} 


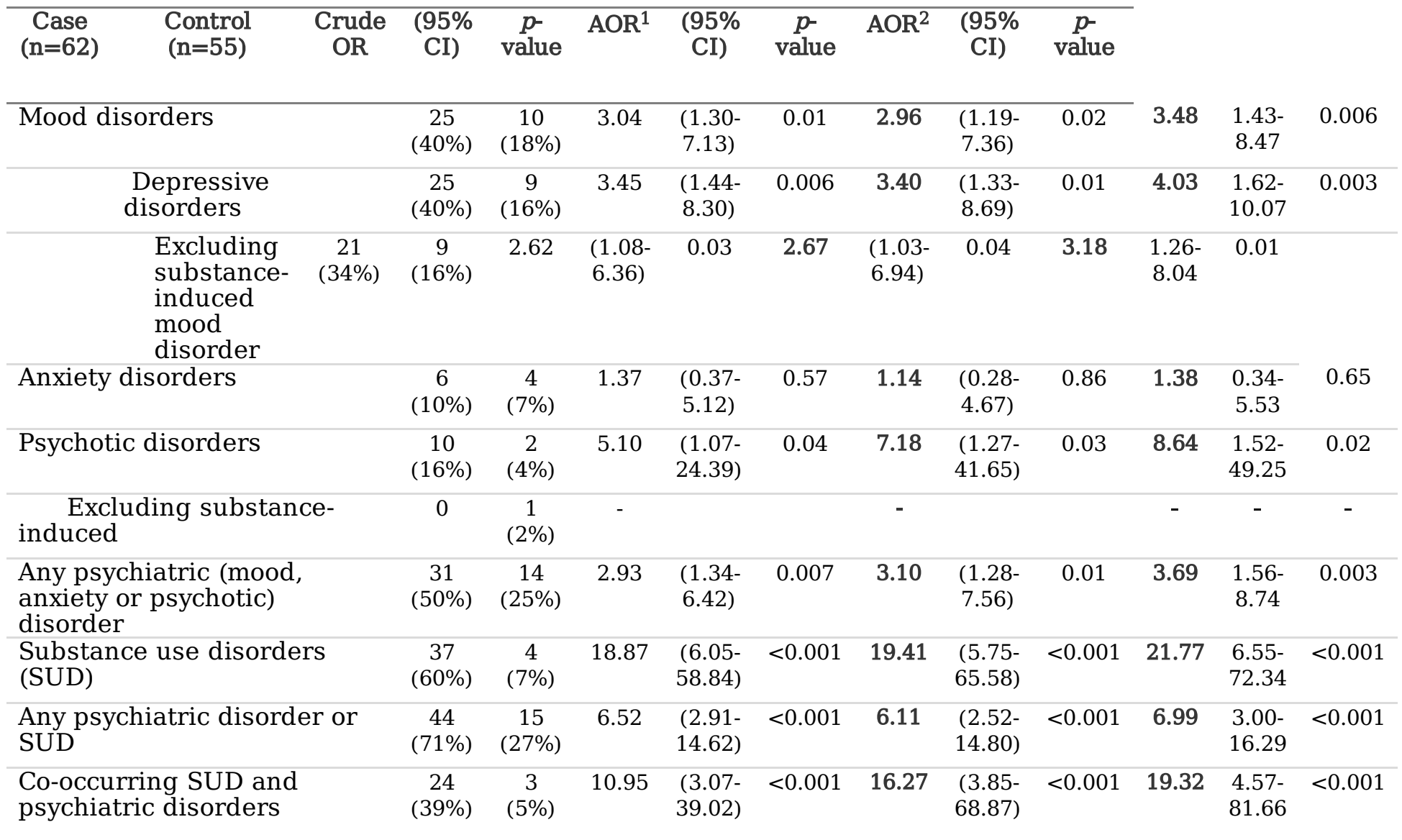

${ }^{1}$ Adjusted for MOS-SSS total score, age and duration of HIV diagnosis

2 Adjusted for age and duration of HIV diagnosis

Abbreviations: AOR - adjusted odds ratio, CI - confidence interval, MOS-SSS - Medical Outcome Survey Social Support Scale, OR - odds ratio, SUD - substance use disorders

Table 7. Comparison of the prevalence of lifetime psychiatric disorders and substance use disorders between the cases and controls

Table 8. Comparisons of the prevalence of lifetime psychiatric disorders and substance use disorders with onset proior to and after HIV diagnosis between the cases and controls 


\begin{tabular}{|c|c|c|c|c|c|c|c|c|}
\hline & \multicolumn{4}{|c|}{$\begin{array}{c}\text { Psychiatric disorders prior to } \\
\text { HIV diagnosis }\end{array}$} & \multicolumn{4}{|c|}{$\begin{array}{l}\text { Psychiatric disorders after HIV } \\
\text { diagnosis }\end{array}$} \\
\hline & $\begin{array}{l}\text { Case } \\
(n=62)\end{array}$ & $\begin{array}{l}\text { Control } \\
(n=55)\end{array}$ & $\begin{array}{c}\text { AOR } \\
(95 \% \\
\text { CI })^{1}\end{array}$ & $\begin{array}{c}p- \\
\text { value }\end{array}$ & $\begin{array}{l}\text { Case } \\
(n=62)\end{array}$ & $\begin{array}{l}\text { Control } \\
(n=55)\end{array}$ & $\begin{array}{c}\text { AOR } \\
(95 \% \\
\text { CI })^{1}\end{array}$ & $\begin{array}{c}p- \\
\text { value }\end{array}$ \\
\hline Mood disorders & $6(10 \%)$ & $5(9 \%)$ & $\begin{array}{l}1.05 \\
(0.28- \\
3.93)\end{array}$ & 0.95 & $\begin{array}{c}19 \\
(31 \%)\end{array}$ & $5(9 \%)$ & $\begin{array}{c}4.73 \\
(1.47- \\
15.20)\end{array}$ & 0.009 \\
\hline Depressive disorders & $6(10 \%)$ & $5(9 \%)$ & $\begin{array}{c}1.02 \\
(0.27- \\
3.5)\end{array}$ & 0.97 & $\begin{array}{c}19 \\
(31 \%)\end{array}$ & $4(7 \%)$ & $\begin{array}{c}6.22 \\
(1.76- \\
21.97)\end{array}$ & 0.005 \\
\hline Anxiety disorders & $5(8 \%)$ & $2(4 \%)$ & $\begin{array}{l}1.36 \\
(0.24- \\
7.81)\end{array}$ & 0.73 & $1(2 \%)$ & $2(4 \%)$ & $\begin{array}{c}0.77 \\
(0.06- \\
10.69)\end{array}$ & 0.85 \\
\hline Psychotic disorders & $1(2 \%)$ & $2(4 \%)$ & $\begin{array}{c}0.37 \\
(0.03- \\
4.98)\end{array}$ & 0.45 & $9(14 \%)$ & 0 & - & \\
\hline $\begin{array}{l}\text { Any psychiatric (mood, anxiety or } \\
\text { psychotic) disorder }\end{array}$ & $\begin{array}{c}10 \\
(16 \%)\end{array}$ & $9(16 \%)$ & $\begin{array}{l}0.94 \\
(0.33- \\
2.62)\end{array}$ & 0.90 & $\begin{array}{c}24 \\
(39 \%)\end{array}$ & 7 (13\%) & $\begin{array}{c}6.36 \\
(1.96- \\
20.65)\end{array}$ & 0.002 \\
\hline Substance use disorders (SUD) & $\begin{array}{c}24 \\
(39 \%)\end{array}$ & $4(7 \%)$ & $\begin{array}{l}10.8 \\
(3.2- \\
36.2)\end{array}$ & $<0.001$ & $\begin{array}{c}15 \\
(24 \%)\end{array}$ & 0 & - & \\
\hline Any psychiatric disorder or SUD & $\begin{array}{c}27 \\
(44 \%)\end{array}$ & $11(20 \%)$ & $\begin{array}{c}2.71 \\
(1.15- \\
6.43)\end{array}$ & 0.02 & $\begin{array}{c}27 \\
(44 \%)\end{array}$ & $7(13 \%)$ & $\begin{array}{c}6.66 \\
(1.08- \\
41.01)\end{array}$ & 0.04 \\
\hline
\end{tabular}

${ }^{1}$ Adjusted for MOS-SSS total score, age and duration of HIV diagnosis Abbreviations: AOR - adjusted odds ratio, CI - confidence interval, MOS-SSS - Medical Outcome Survey Social Support Scale, SUD - substance use disorders

Table 9. Univariate analysis of the factors affecting the prevalence of lifetime psychiatric disorders in the cases 


\section{Sociodemographic factors}

Non-Chinese 3

$\mathrm{Age}^{3}$

34.68 (7.90)

Bisexual

Secondary education only

Unemployed

Monthly income $\$ 10000$ or below

Single/divorced

Lived alone

Family history of psychiatric illness

MOS-SSS total ${ }^{3}$

HIV-related factors

Duration of HIV diagnosis ${ }^{4}$

Stage B or C

Lifetime psychiatric diagnosis

Yes $(\mathrm{n}=31)^{1}$

No $(n=31)^{1}$

$p$-value ${ }^{2}$

ART initiated

$34.68(7.8$
4

4

2

0.64

ART adherence $<95 \%$

6

33.19

(8.75)

0.45

1

0.16

6

10

0.25

9

21

8

9

55.74 (13.76)

3

0.28

4

0.12

17

0.30

6

0.54

7

0.56

5

Virologic failure

$5[1,7]$

$63.84(15.18)$

0.03

CD4 $<200 / \mu \mathrm{L}$

HCV co-infection

$3 / 21$

$1[0,2]$

0.003

31

$5 / 23$

0.70

5

30

1.00

$4 / 28$

$2 / 30$

0.42

1

2

$3 / 29$

0.71

0

1.00

$2 / 30$

1.00

\section{Substance-related factors}

Any SUD

24

13

0.004

Methamphetamine use factors

Dependence

$\begin{array}{ccc}22 & < & <0.001 \\ & & 0.004\end{array}$

$\begin{array}{cc}22 & <0.001 \\ & 0.004\end{array}$

Duration of regular use

Irregular or no use

Weekly use for 2 years or less

Weekly use for more than 2 years

Days of use in last month ${ }^{4}$

Age of first use $(n=60)^{3}$

Not exclusive in chemsex

Increased or started after HIV diagnosis

$\begin{array}{cc}8 & 18 \\ 13 & 12 \\ 10 & 1\end{array}$

$2[0,16]$

30.03 (9.19)

$1[0,3]$

0.17

22

29.61 (8.94)

0.86

18

11

0.006

Other psychotropic substance use factors

Ever monthly use of MDMA

Ever monthly use of GHB

\begin{tabular}{ccc}
11 & 5 & 0.08 \\
15 & 11 & 0.30 \\
$5[4,6]$ & $4[3,6]$ & 0.11 \\
\hline
\end{tabular}

Number of substances ever used ${ }^{4}$

1 unless otherwise stated for specific variables

${ }^{2} t$ test or Mann Whitney $\mathrm{U}$ test for continuous variable, chi-square or Fisher exact test for categorical variables

3 means and standard deviations are presented

4 medians and interquartile ranges are presented

Abbreviations: ART - antiretroviral treatment, HCV - hepatitis C virus, GHB - $g$-hydroxybutyrate, MDMA - 3,4-

methylenedioxymethamphetamine, MOS-SSS - Medical Outcome Survey Social Support Scale, SDS - Severity of Dependence Scale, SUD

- substance use disorders

Table 10. Multivariate loistic regression analysis of the factors affecting the prevalence of lifetime psychiatric disorders in the cases 


\begin{tabular}{|c|c|c|c|c|c|c|c|c|}
\hline & \multicolumn{2}{|c|}{ Model 1} & \multicolumn{2}{|c|}{ Model 2} & \multicolumn{2}{|c|}{ Model 3} & \multicolumn{2}{|c|}{ Model 4} \\
\hline & $\begin{array}{c}\mathrm{AOR}^{1} \\
(95 \% \mathrm{CI})\end{array}$ & $p$-value & $\begin{array}{c}\mathrm{AOR}^{1} \\
(95 \% \mathrm{CI})\end{array}$ & $p$-value & $\begin{array}{c}\mathrm{AOR}^{1} \\
(95 \% \mathrm{CI})\end{array}$ & $p$-value & $\begin{array}{c}\mathrm{AOR}^{1} \\
(95 \% \mathrm{CI})\end{array}$ & $p$-value \\
\hline $\begin{array}{l}\text { Substance use } \\
\text { disorders } \\
\text { (Model 1) }\end{array}$ & $\begin{array}{c}6.80 \\
(1.38- \\
33.62)\end{array}$ & 0.02 & & & & & & \\
\hline $\begin{array}{l}\text { Methamphetamine } \\
\text { dependence } \\
\text { (Model 2) }\end{array}$ & & & $\begin{array}{c}6.63 \\
(1.53- \\
28.72)\end{array}$ & 0.01 & & & & \\
\hline $\begin{array}{l}\text { Methamphetamine } \\
\text { use beyond chemsex } \\
\text { (Model 3) }\end{array}$ & & & & & $\begin{array}{l}4.76 \\
(1.17- \\
19.41)\end{array}$ & 0.03 & & \\
\hline $\begin{array}{l}\text { weekly use of } \\
\text { methamphetamine for } \\
2 \text { years or less } \\
\text { (Model 4) }\end{array}$ & & & & & & & $\begin{array}{l}1.76 \\
(0.38- \\
8.09)\end{array}$ & 0.47 \\
\hline $\begin{array}{l}\text { weekly use of } \\
\text { methamphetamine for } \\
\text { more than } 2 \text { years } \\
\text { (Model } 4 \text { ) }\end{array}$ & & & & & & & $\begin{array}{c}18.60 \\
(1.26- \\
274.69)\end{array}$ & 0.03 \\
\hline $\begin{array}{l}\text { Ever MDMA monthly } \\
\text { use } \\
\text { (Model 4) }\end{array}$ & & & & & & & $\begin{array}{c}4.41 \\
(0.79- \\
25.67)\end{array}$ & 0.10 \\
\hline $\begin{array}{l}\text { Duration of } \\
\text { HIV diagnosis } \\
\text { (Models 1-4) }\end{array}$ & $\begin{array}{l}1.87 \\
(1.28- \\
2.72)\end{array}$ & 0.001 & $\begin{array}{l}1.78 \\
(1.23- \\
2.52)\end{array}$ & 0.002 & $\begin{array}{l}1.73 \\
(1.23- \\
2.43)\end{array}$ & 0.002 & $\begin{array}{l}1.77 \\
(1.22- \\
2.58)\end{array}$ & 0.003 \\
\hline Model summary & $\begin{array}{l}\text { Cox \& Snel } \\
\text { Hosmer-Le1 } \\
\text { test: Chi-sq } \\
\text { df } 7 p=0.82\end{array}$ & $\begin{array}{l}R^{2}: 0.41 \\
\text { leshow } \\
\text { lare } 3.7\end{array}$ & $\begin{array}{l}\text { Cox \& Snell } \\
\text { Hosmer-Lem } \\
\text { test: Chi-squ } \\
\text { df } 7 p=0.45\end{array}$ & $\begin{array}{l}R^{2}: 0.42 \\
\text { eshow } \\
\text { are } 6.8\end{array}$ & $\begin{array}{l}\text { Cox \& Snell } \\
\text { Hosmer-Lem } \\
\text { test: Chi-squ } \\
\text { df } 7 p=0.18\end{array}$ & $\begin{array}{l}R^{2}: 0.39 \\
\text { eshow } \\
\text { are } 10.3\end{array}$ & $\begin{array}{l}\text { Cox \& Snell } 1 \\
\text { Hosmer-Lem } \\
\text { test: Chi-squ } \\
\text { df } 7 p=0.10\end{array}$ & $\begin{array}{l}R^{2}: 0.42 \\
\text { eshow } \\
\text { are } 12.0\end{array}$ \\
\hline
\end{tabular}

${ }^{1}$ Factors were adjusted for the other variables as shown in individual models Abbreviations: AOR - adjusted odds ratio, CI - confidence interval, MDMA - 3,4-methylenedioxymethamphetamine

\section{Figures}




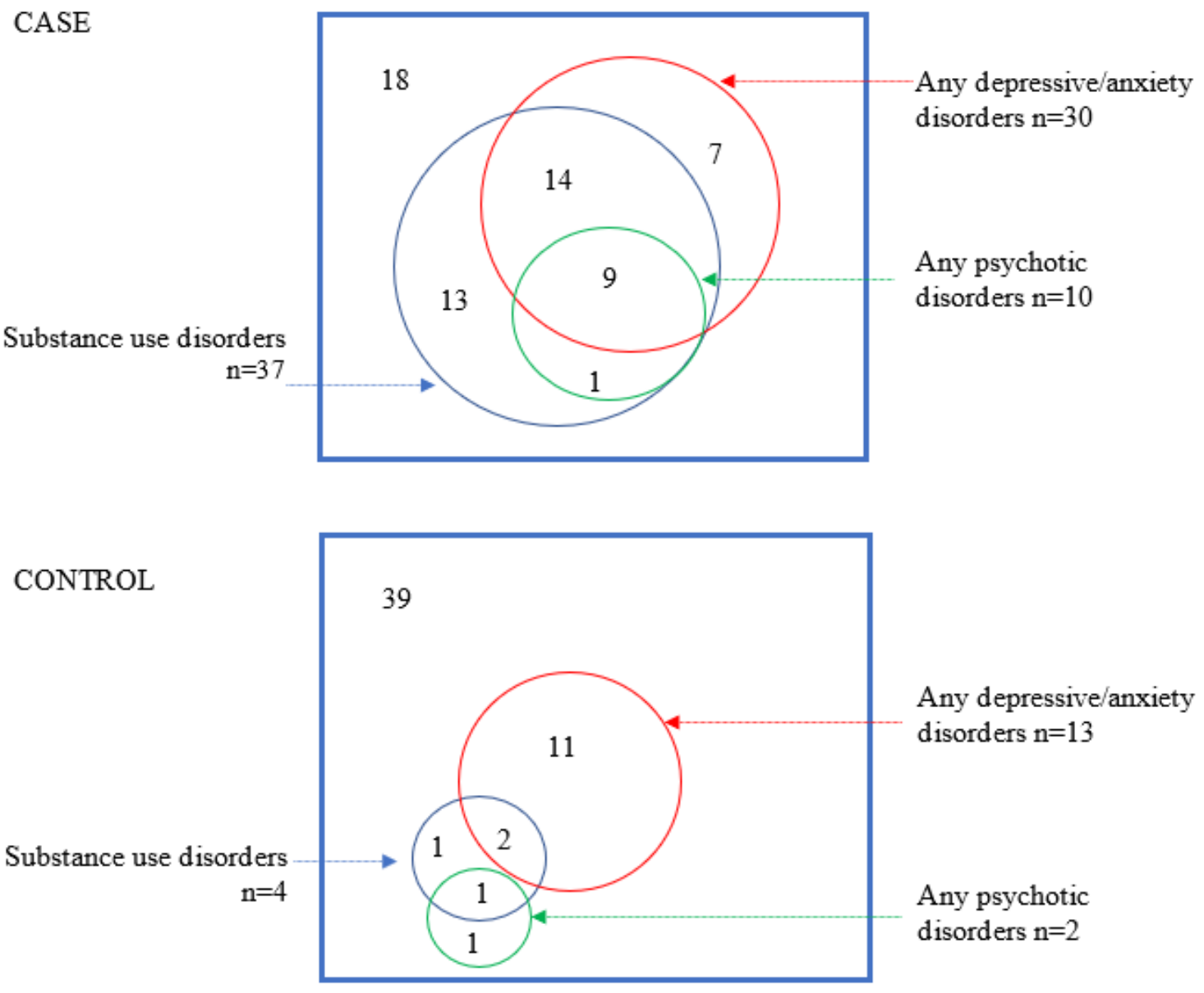

Figure 1 